\title{
Effects of word familiarity and delay of testing on recognition memory performance
}

\author{
STEVEN D. KEENER and PHILIP TOLIN \\ Central Washington State College, Ellensburg, Washington 98926
}

\begin{abstract}
Eighty subjects were shown either 100 rare words or 100 common words and tested for recognition memory either immediately or after a 48-h delay. On the immediate test, subjects in the rare word condition made more correct decisions. Delay of testing affected the proportion of correct decision, hit rates, and false-alarm rates. The data suggest a temporal decrement in $\mathrm{d}^{\prime}$ for both word conditions.
\end{abstract}

Recognition memory for rare words typically has been found to be superior to that for common words (Gorman, 1961; McCormack \& Swenson, 1972; Schwartz \& Rouse, 1961; Shepard, 1967). Following Egan (1958), several authors have evaluated the results of recognition memory experiments in terms of signal detection theory and have suggested differences in the discriminability index, $\mathrm{d}^{\prime}$ or $\mathrm{d}_{\mathrm{s}}$, associated with the two classes of words (Allen \& Garton, 1968; Rundle, 1970; Schulman, 1967; Schulman \& Lovelace, 1970).

In previous studies of the effects of word familiarity on recognition memory performance, the memory test has been given shortly after exposure to the to-be-remembered list of words. Over the small retention intervals that have been employed, the declines in performance with rare and common words have been comparable (Underwood \& Freund, 1970).

The purpose of the present research was to examine recognition memory for rare and common words both immediately and following a longer retention interval than customarily has been used. It was expected that, as in previous research, when testing occurred shortly after presentation of word lists, recognition memory for rare words would be superior to that for common words, and that this difference would be associated with differences in $\mathrm{d}^{\prime}$, rather than differences in subjects' response criteria, $\beta$. When testing was delayed by $48 \mathrm{~h}$, it was expected that recognition memory performance for both rare and common words would decline. Of interest were the relative extents of these time-related decrements (i.e., the Word Familiarity by Test Delay interaction) and the source of this decline either in changes in item discriminability ("memory strength" [Kintsch, 1970]) or in subjects' criteria of judgment.

This paper is based on a master's thesis completed by the first author under the direction of the second author. Steven D. Keener is now at Rice University.

\section{METHOD}

Eighty undergraduate volunteers ( 22 males and 58 females) were randomly assigned to one of four experimental conditions, based on word familiarity (rare or common) and test delay (0 or $48 \mathrm{~h}$ ).

Each subject viewed a study list of either 100 common words or 100 rare words taken randomly from the list constructed by Schulman and Lovelace (1970). Words were presented individually via a Kodak Carousel Model 800 slide projector, with exposure times of $2.5 \mathrm{sec} /$ item and interitem intervals of $.8 \mathrm{sec}$. Paper-and-pencil tests of recognition memory were then administered either immediately following presentation of the study list or $48 \mathrm{~h}$ later. The test consisted of the 100 old words randomly interspersed with 100 new words having the same familiarity level. Subjects were instructed to mark each of the words that they thought had been presented in the study list. Four different presentation orders of test items were used at each level of word familiarity in order to minimize the risk of peculiarities associated with a particular order.

\section{RESULTS AND DISCUSSION}

Analyses of main and interactive effects of word familiarity and test delay were conducted for the following dependent measures: (a) proportion of correct decisions, (b) total number of responses (i.e.. items marked), (c) proportion of hits, (d) proportion of false alarms, (e) $d^{\prime}$, and (f) $\beta$. The latter two measures were obtained following Hochhaus (1972). Group means and standard deviations for each measure are shown in Table 1.

The immediate test of recognition memory basically was considered as an attempt to replicate earlier research. On this test, subjects in the rare word condition made significantly more correct decisions $[F(1,76)=6.55, p<.05]$ than did subjects in the common word condition. However, this consistency with earlier results did not extend to the other dependent measures; there were no other significant effects of word familiarity with the immediate test alone $(p>.05)$. Strength of association was estimated by an omega-squared test (Kirk, 1968), which indicated that the word familiarity main effect accounted for $8.1 \%$ of the variance in the number of correct decisions on the immediate test. 
Table 1

Means and Standard Deviations of the Six Dependent Measures

\begin{tabular}{|c|c|c|c|c|c|c|c|c|}
\hline \multirow[b]{4}{*}{ Dependent Measure } & \multicolumn{8}{|c|}{ Condition } \\
\hline & \multicolumn{4}{|c|}{ Common Words } & \multicolumn{4}{|c|}{ Rare Words } \\
\hline & \multicolumn{2}{|c|}{ Immediate Test } & \multicolumn{2}{|c|}{ Delayed Test } & \multicolumn{2}{|c|}{ Immediate Test } & \multicolumn{2}{|c|}{ Delayed Test } \\
\hline & Mean & SD & Mean & SD & Mean & SD & Mean & SD \\
\hline Total number of responses & 67.60 & 24.92 & 74.00 & 31.21 & 68.00 & 15.17 & 67.50 & 30.46 \\
\hline Proportion of correct decisions & .68 & .071 & .57 & .045 & .72 & .063 & .62 & .046 \\
\hline Proportion of hits & .51 & .168 & .44 & .155 & .56 & .107 & .45 & .159 \\
\hline Proportion of FAs & .16 & .114 & .30 & .170 & .12 & .090 & .22 & .160 \\
\hline$d^{\prime}$ values & 1.18 & .543 & .45 & .303 & 1.50 & .552 & .80 & .448 \\
\hline$\beta$ values & 2.93 & 3.328 & 1.50 & 1.237 & 3.71 & 3.910 & 2.44 & 2.985 \\
\hline
\end{tabular}

The effect of delay of testing was more substantial. Subjects made fewer correct decisions on the delayed test than on the immediate test $[F(1,76)=68.05$, $\mathrm{p}<.001]$. The test delay variable accounted for $42 \%$ of the variance in the proportion of correct decisions. Further, delay of testing was associated with a decrease in the hit rate $[F(1,76)=7.51, p<.01]$ and an increase in the proportion of false alarms $[F(1,76)=15.49, p<.001]$. Omega-squared values indicated that test delay accounted for $7.6 \%$ and $15 \%$ of the variance in these two measures, respectively. These findings suggest a time-related change in the discriminability of items in memory, rather than changes in subjects' criteria. Consistent with this interpretation was a significant temporal decrement in $\mathrm{d}^{\prime}$ values $[\mathrm{F}(1,76)=45.14, \mathrm{p}<.001]$, with $33 \%$ of the variance in $d^{\prime}$ accounted for by the test delay treatment. Changes in $\beta$ values were not significant $(\mathrm{p}<.05)$.

Finally, there was no evidence of a significant Word Familiarity by Test Delay interaction for any of the dependent measures, reflecting comparable performance changes over time for both levels of word familiarity.

\section{REFERENCES}

Allen, L. R., \& Garton, R. F. The influence of wordknowledge on the word-frequency effect in recognition memory. Psychonomic Science, 1968, 10, 401-402.
EgAN, J. P. Recognition memory and the operating characteristic (Technical Note AFCRC-TN-58-51). Bloomington, Indiana: Hearing and Communication Laboratory, Indiana University, 1958.

Gorman, A. M. Recognition memory for nouns as a function of abstractness and frequency. Journal of Experimental Psychology, 1961, 61, 23-29.

Hochraus, L. A table for the calculation of $d^{\prime}$ and $B$. Psychological Bulletin, 1972, 77, 375-376.

KINTSCH, W. Learning, memory, and conceptual processes. New York: Wiley, 1970.

KIRK, R. E. Experimental design: Procedures for the behavioral sciences. Belmont, California: Brooks/Cole, 1968.

McCormack, P. D., \& Swenson, A. L. Recognition memory for common and rare words. Journal of Experimental Psychology, $1972,95,72-77$.

Rundle, S. A. An experimental and theoretical study of recognition memory (Doctoral dissertation, University of California, Los Angeles, 1969). Dissertation Abstracts International, 1970, 30, 5265B. (University Microfilms No. 70-8195).

Schulman, A. I. Word length and rarity in recognition memory. Psychonomic Science, 1967, 9, 211-212.

Schulman, A. I., \& Lovelace, E. A. Recognition memory for words presented at a slow or rapid rate. Psychonomic Science, 1970, 21, 99-100.

SChWARTZ, F., \& Rouse, R. D. The activation and recovery of associations. Psychological Issues, 1961, 3, Whole No. 1.

SHEPARD, R. N. Recognition memory for words, sentences, and pictures. Journal of Verbal Learning and Verbal Behavior, 1967. 6. $156-163$.

Underwood, B. J., \& Freund, J. S. Word frequency and short-term recognition memory. American Journal of Psychology, 1970, 83, 343-351.

(Received for publication October 30, 1975.) 